\title{
Assessment of Thermal Comfort in High Humidity Environments. The Case of an Indoor Aquatic Centre in Western Macedonia, Greece
}

\author{
Giannis Papadopoulos*, Evangelos I. Tolis, Giorgos Panaras \\ Deparment of Mechanical Engineering, University of Western Macedonia, Bacola \& Sialvera, 50100 Kozani, Greece
}

\begin{abstract}
Investigation of thermal comfort in various types of buildings is a rather intense research activity by recent years. However, thermal comfort studies in sport facilities are very limited. Aquatic centers present an interesting field, in terms of Indoor climate and Air Quality, due to the fact that environmental quality is affected from high percentage of relative humidity, as well as from the emission of chemicals used for water disinfection. The proposed work presents a measurement campaign in a naturally ventilated aquatic centre in Western Macedonia, Greece. The campaign was performed through summer time, including measurements of thermal comfort and IAQ parameters. As far as thermal comfort is concerned, the approach of Fanger, as well as the adaptive one are considered. The results support the redesigning of the air-conditioning concept implemented, to ensure satisfactory thermal comfort conditions; energy consumption increase aspects should be taken into account.
\end{abstract}

Peer-review under the responsibility of the organizing committee of the ICMB21.

Keywords: Aquatic centre; Thermal comfort; Indoor climate conditons; $\mathrm{CO}_{2}$ levels

\section{Introduction/Background}

Indoor sport facilities have experienced exponential demand over the past few decades. The indoor swimming pools are the second most popular sport facilities worldwide and they also have the highest energy consumption amongst sports centres and outdoor pools ${ }^{[1]}$. Thus, it is important to investigate the indoor environmental quality (IEQ), noting that thermal comfort presents special interest due to the high levels of relative humidity, while indoor air quality (IAQ) is also important, having in mind potential ventilation insufficiency, combined to the emission of pool water cleaning disinfectants, and their potential reaction to indoor air substances. Given the high demand for indoor environmental conditions regulation, air-conditioning can be critical, highlighting energy consumption aspects.

In the proposed work, a measurement campaign in an indoor aquatic centre in Kozani, Western Macedonia, Greece, is presented. Kozani is located in Climate zone D according to the Greek version of Energy Performance of Buildings Directive (EPBD), which characterized of cold winters and mild summers. The campaign was performed through summer time when the aquatic centre is naturally ventilated (cooling devices are not installed) and aims to assess the environmental parameters and thermal comfort according to the ASHRAE 55/2017 ${ }^{[2]}$ and EN $15251^{[3]}$.

\section{Methodology}

The proposed methodology is based on experimental and theoretical analysis. Experimental investigation includes extensive measurement campaign, carried out in the period of June $6^{\text {th }}$ to July $7^{\text {th }}$, regarding indoor and outdoor climate thermal parameters (air temperature, radiant temperature, relative humidity, air velocity), as well as IAQ ones, namely $\mathrm{CO}_{2}$ concentration, through the use of relevant portable sensors. The results of the thermal parameters along with physical parameters of metabolic rate and clothing can be exploited for the assessment of indoor climate and thermal comfort. The main models for the evaluation of the thermal comfort refer to the Predicted Mean Vote (PMV) approach (based on Fanger's model ${ }^{[4]}$ and the adaptive model ${ }^{[3]}$, noting that the latter is more suitable for naturally ventilated spaces, where outdoor conditions influence indoor thermal comfort; this is the case of the studied centre, by summer time.

\section{Results/Discussion}

In the following table (Table 1), the average, minimum and maximum values for thermal comfort parameters, together with $\mathrm{CO}_{2}$ concentration, are presented. The values, corresponding to logging interval of 10', refer to the average indication of all sensors for the periods the aquatic centre was mostly crowded; these periods concern 16-20 th of June and 1-5 th $^{\text {th }}$ July, during 16:00-20:00. By this time, most windows are usually opened, allowing some degree of natural ventilation, as can be seen from the low $\mathrm{CO}_{2}$ concentration. As regards the indoor air temperature, this is a little bit higher than the outdoor, due to the inadequate thermal insulation and the high radiant temperature. Relative humidity values present in general acceptable values during operation time,

\footnotetext{
* Giannis Papadopoulos. +302461056725. g.papadopoulos@uowm.gr
} 


\section{ICMB21}

noting though that natural ventilation, due to open windows, clearly limits the evaporation rate of pool water. By the time windows are closed, high values of moisture, reaching saturation are observed.

Table 1. Indoor and outdoor air environmental parameters during measurement periods

\begin{tabular}{|l|c|c|c|c|c|c|}
\hline & \multicolumn{3}{|c|}{ Indoor space } & \multicolumn{3}{c|}{ Outdoor area } \\
\hline Parameter & Mean & Min & Max & Mean & Min & Max \\
\hline Air Temperature $\left({ }^{\circ} \mathrm{C}\right)$ & 30.8 & 23.4 & 37.4 & 30.3 & 18.6 & 36.3 \\
\hline RH $(\%)$ & 49.85 & 32.3 & 77.0 & 42.7 & 16.7 & - \\
\hline Radiant Temperature $\left({ }^{\circ} \mathrm{C}\right)$ & 31.96 & 23.37 & 36.87 & - & - & - \\
\hline $\mathrm{CO}_{2}(\mathrm{ppm})$ & 539.6 & 364.3 & 925.5 & - & - \\
\hline Wind Speed $(\mathrm{m} / \mathrm{s})$ & 0.09 & 0.01 & 0.30 & 0.84 & 0.40 & 1.28 \\
\hline
\end{tabular}

Figure 1, shows the diagram of the adaptive model. Operation temperature is the average of the air and radiant temperature, as the average value of wind speed is under $0.2 \mathrm{~m} / \mathrm{s}^{[4]}$. As can be seen in Figure 1, the operative temperature for most days exceeds the acceptable limits. Concerning the ASHRAE Standard 55-2017 $7^{[2]}$, only two days are within the acceptable limits, while for the EN15251 standard ${ }^{[3]}$, operative temperatures for four days lie between the limits of III category. Results demonstrate that the thermal environment of the aquatic centre needs to be significantly improved during summer period, in order to establish thermal comfort conditions.

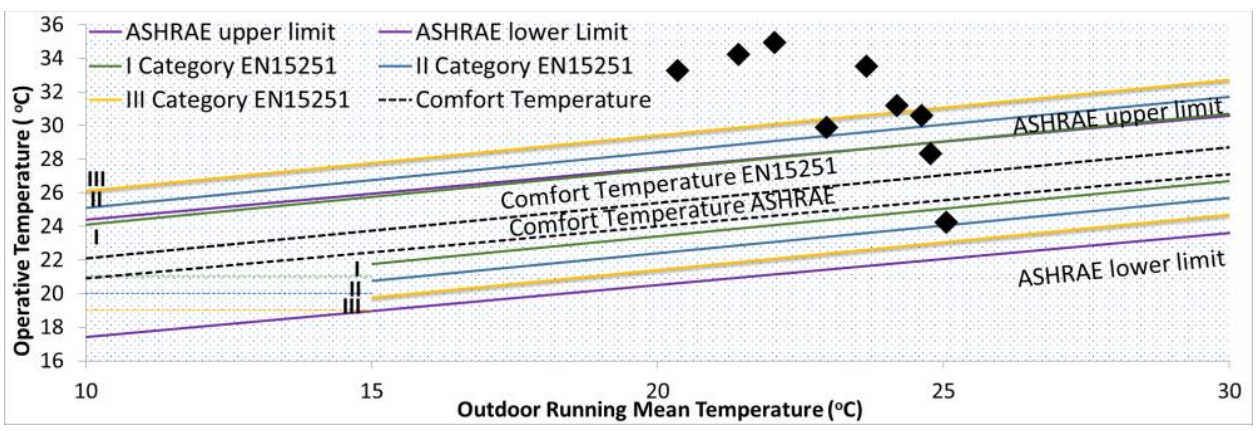

Figure 1. Adaptive comfort chart for free running aquatic centre

More specifically, mechanical ventilation should be applied, together with cooling; this would allow the regulation of temperature by summer time, which is burdened by natural ventilation, as depicted through the analysis. At the same time, humidity control would be feasible and establishment of satisfactory hygienic rates, without the effect on temperature. In addition, the placement of swimming pool cover, would eliminate night humidity high values, while that of shading devices would decrease radiant temperature. Mechanical ventilation would act positively by winter time as well as. The drawback of the discussed interventions is related to the increased energy consumption.

\section{Conclusions}

The performed measurements of indoor environmental parameters, by summer time, demonstrate high values of air and radiant temperatures, while relative humidity and wind speed are receivable, by occupancy time. The $\mathrm{CO}_{2}$ concentration is within the acceptable limits due to the open windows. Analysis with the adaptive comfort model, as the studied building by summer time is free-running, demonstrated that the correlation of operative temperature with mean outdoor temperature was over the acceptable limits for the majority of the days, due to the high operative temperature.

The results can be exploited towards the improvement of indoor environment, indicating the necessity of mechanical ventilation and cooling application, instead of natural ventilation, in order to decrease operative temperature, regulate humidity and ensure satisfactory IAQ. Shading devices and swimming pool cover can also be important for the indoor environment, while energy consumption is expected to increase. Future research may concentrate on the generalization on thermal comfort assessment findings for the complete year, as well as on their correlation with the energy aspects mentioned above.

\section{References}

[1] E. Trianti-Stourna, K. Spyropoulou, C. Theofylaktos, K. Droutsa, C. Balaras, M.Santamouris, N. Papanikolaou (1998), Energy conservation strategies for sports centres: Part B. Swimming Pools Energy Build. 27(2), 123-135.

[2] ASHRAE, 2017. Standard 55-2017. Thermal Environmental Conditions for Human Occupancy. Atlanta.

[3] CEN, 2012. EN15251. Indoor environmental input parameters for design and assessment of energy performance of buildings- addressing indoor air quality, thermal environment, lighting and acoustic. Brussels.

[4] CEN, 2005. EN ISO 7730. Ergonomics of the thermal environment - Analytical determination and interpretation of thermal comfort using calculation of the PMV and PPD indices and local thermal comfort criteria. Brussels. 